\title{
Lithobius (Monotarsobius) monoforaminis sp. n., a new species of lithobiid centipede from central China (Chilopoda, Lithobiomorpha, Lithobiidae)
} \author{
Jiangsu 210008, P. R. China \\ † urn:lsid:zoobank.org:author:8A6B6C85-18B0-46DC-A8C5-3BEA704F63E3 \\ † urn:lsid:zoobank.org:author:6A92478C-79B7-4330-AFCE-215COD1E9796 \\ § urn:lsid:zoobank.org:author:514BD91A-8783-4DE0-951A-7649B2A769EA \\ | urn:lsid:zoobank.org:author:14250E43-D3F6-4E43-8DF7-DA2F6C6F801A \\ II urn:lsid:zoobank.org:author:60325E87-C003-4AC4-8A22-0E8ECABCB4C4 \\ Corresponding author: Huiqin Ma (mhq008@yahoo.com)
}

Huiqin Ma ${ }^{1, \dagger}$, Sujian Pei ${ }^{2, \ddagger}$, Dayong Wu ${ }^{2, \S}$, Hongjun Lin²,l, Yonghua Gai ${ }^{3, \pi}$

I Scientific Research Office, Hengshui University, Hengshui, Hebei 053000, P. R. China 2 Department of Life Sciences, Hengshui University, Hengshui, Hebei 053000, P. R. China 3 State Key Laboratory of Palaeobiology and Stratigraphy, Nanjing Institute of Geology and Palaeontology, Chinese Academy of Sciences; Nanjing,

Academic editor: Marzio Zapparoli | Received 31 January 2012 | Accepted 17 April 2012 | Published 14 May 2012

urn:lsid:zoobank.org:pub:A8FOE269-29BB-4C6F-B575-3FA298B01225

Citation: Ma H, Pei S, Wu D, Lin H, Gai Y (2012) Lithobius (Monotarsobius) monoforaminis sp. n., a new species of lithobiid centipede from central China (Chilopoda, Lithobiomorpha, Lithobiidae). ZooKeys 193: 79-87. doi: 10.3897/ zookeys. 193.2802

\begin{abstract}
The present paper describes a new species Lithobius (Monotarsobius) monoforaminis sp. n. (Lithobiomorpha: Lithobiidae) recently discovered from Shaanxi and Shanxi provinces, Central China. Morphologically it resembles L. (M.) minimus Farzalieva, 2006 from Eastern Kazakhstan, but could be well distinguished from the latter having only one pore on the coxae of legs 12-15 and different plectrotaxy, and by lacking a wart on the male tibia 15 . A key to the Chinese Lithobius (Monotarsobius) species is presented.
\end{abstract}

\section{Keywords}

Lithobiidae, Lithobius (Monotarsobius) monoforaminis, China, identification key

Copyright Huiqin Ma et al. This is an open access article distributed under the terms of the Creative Commons Attribution License 3.0 (CC-BY), which permits unrestricted use, distribution, and reproduction in any medium, provided the original author and source are credited. 


\section{Introduction}

The centipede subgenus Lithobius (Monotarsobius) Verhoeff, 1905 (Lithobiomorpha: Lithobiidae) comprises 114 species known from Asia, Europe, and North Africa (Pocock 1895; Trotzina 1895; Attems 1901, 1904; Dobroruka 1960, 1979; Zalesskaja 1978; Farzalieva and Zalesskaja 2002; Farzalieva 2006; Zapparoli 2006; Zapparoli and Edgecombe 2011; Dányi and Tuf 2012). It is characterized by the presence of fused tarsi of legs 1-13 and antennal articles fixed at 20 or thereabouts (Eason 1992).

Sixty-seven species and subspecies of Lithobiomorpha are hitherto known from China (Attems 1938, 1953; Takakuwa 1939, 1940, 1941, 1942; Takakuwa and Takashima 1949; Chamberlin and Wang 1952; Wang 1959, 1963; Zalesskaja 1978; Wang and Mauriès 1996; Zhang 1996; Eason 1992, 1997; Chao 2005; Zapparoli 2006; Ma et al. 2007a, 2007b, 2008a, 2008b, 2009; Pei et al. 2011), of which only nine belong to subgenus Monotarsobius. Herewith we describe a new species of Monotarsobius which was recently found in the Shaanxi and Shanxi provinces. This is the first reliable record of the subgenus in this region of China.

\section{Methods}

All specimens were hand-collected under leaf litter or stones. The material was examined with the aid of a Motic-C microscope, made in China. Colour description is based on specimens in 75\% alcohol, and body length is measured from anterior margin of the cephalic plate to posterior end of postpedal tergite. Type specimens are deposited in the College of Life Sciences, Hebei University, Baoding, China. Terminology for external anatomy follows Bonato et al. (2010).

The following abbreviations are used in the text and tables: $\mathrm{T}, \mathrm{TT}=$ tergite, tergites; $\mathrm{S}, \mathrm{SS}=$ sternite, sternites; $\mathrm{C}=$ coxa, $\mathrm{t}=$ trochanter, $\mathrm{P}=$ prefemur, $\mathrm{F}=$ femur, $\mathrm{Ti}$ = tibia, $\mathrm{a}=$ anterior, $\mathrm{m}=$ median, $\mathrm{p}=$ posterior .

\section{Taxonomy}

\section{Lithobiidae Newport, 1844}

Lithobius (Monotarsobius) monoforaminis sp. n.

urn:lsid:zoobank.org:pub:A8F0E269-29BB-4C6F-B575-3FA298B01225

http://species-id.net/wiki/Lithobius_monoforaminis

Material examined. Holotype. $\delta$ (Fig. 1), body length $7.7 \mathrm{~mm}$, cephalic plate $0.76 \mathrm{~mm}$ long, $0.76 \mathrm{~mm}$ broad, Huashan Mountain, Huayin County, Xian City, Shaanxi Province, $34^{\circ} 31^{\prime} \mathrm{N}, 110^{\circ} 05^{\prime} \mathrm{E}, 438 \mathrm{~m}, 10$ October 2005, leg. Yong-hua Gai, Hui-qin Ma. 
Paratypes. 5 우, $3 \widehat{\diamond}$, same data as holotype.

Other materials. 13 우, $12 \hat{\jmath} \widehat{\jmath}$, Yongji County, Yuncheng City, Shanxi Province, $34^{\circ} 51^{\prime} \mathrm{N}, 110^{\circ} 29^{\prime} \mathrm{E}, 388 \mathrm{~m}, 8$ October 2005, leg. Yong-hua Gai, Hui-qin Ma.

Etymology. The specific name refers to the presence of a single pore on the coxae of legs $12-15$.

Diagnosis. A Lithobius (Monotarsobius) species with antennae composed of 16-22 articles, commonly 20 articles; 6-7 ocelli on each side, arranged in two irregular rows, the two posterior ocelli comparatively large; Tömösváry's organ moderately small, slightly smaller than adjoining ocelli, or equal to adjoining ocelli; $2+2$ coxosternal teeth; porodonts moderately slender, posterolateral to lateral tooth; posterior angles of all tergites without triangular projections; coxal pores 1111, round; female gonopods with $2+2$ moderately small, coniform spurs; terminal claw tridentate; male gonopods short and small, with 1-2 long setae on the terminal segment.

Description. Body length: 6.9-8.6 mm, cephalic plate 0.75-0.96 mm long, 0.75$0.96 \mathrm{~mm}$ wide.

Colour: basal antennal articles pale yellow-brown to chocolate, transition to yellow brownish from the twelfth article onwards, distalmost one yellow-brownish; tergites yellow-brown; cephalic plate, TT 1,14 and 15 pale yellow-brown; pleural region pale grey with a yellowish hue, SS pale grey to grey with a purple hue; distal part of forcipules brown, basal and proximal parts of forcipules, forcipular coxosternite and SS 14 and 15 pale yellow-brown; all legs pale purple to grey, basal tarsus pale purple, distal tarsus yellow-brown.

Antennae: composed of 16-22 articles, commonly 20+20 articles; basal article long about equal to wide, the second markedly longer than wide, following articles gradually shortening, distal article much longer than wide, up to 2.0-2.5 times as long as wide; abundant setae on the antennal surface, less so on the basal articles, gradually increase in density towards the fourth article, then more or less constant in number.

Cephalic plate: smooth, convex, pigment concentrated as close netlike vein, long equal to wide; tiny setae emerging from pores and long setae scattered sparsely over the whole surface; frontal marginal ridge with shallow anterior median furrow; posterior margin of cephalic plate straight (Fig. 1).

Ocelli: six-seven oval to rounded on each side (Fig. 2) situated in two irregular rows; terminal two comparatively large, other ocelli about equal in size; ocelli domed, translucent, usually darkly pigmented.

Tömösváry's organ: comparatively small (Fig. 2-To), nearly rounded; situated at anterolateral margin of cephalic plate, slightly smaller than the adjoining ocelli or equal in size.

Forcipular coxosternite: subtrapezoidal (Fig. 3), anterior margin narrow, external side lightly longer than internal side; median diastema moderately deep, V-shaped; anterior margin with $2+2$ teeth; porodonts comparatively sharp, lying posterolateral to the lateral tooth (Fig. 3); some scattered setae on the ventral side of coxosternite.

Tergites: smooth, without wrinkles, backside slightly hunched; $\mathrm{T} 1$ posterolaterally narrower than anterolaterally, generally trapeziform, narrower than T 3 and the 


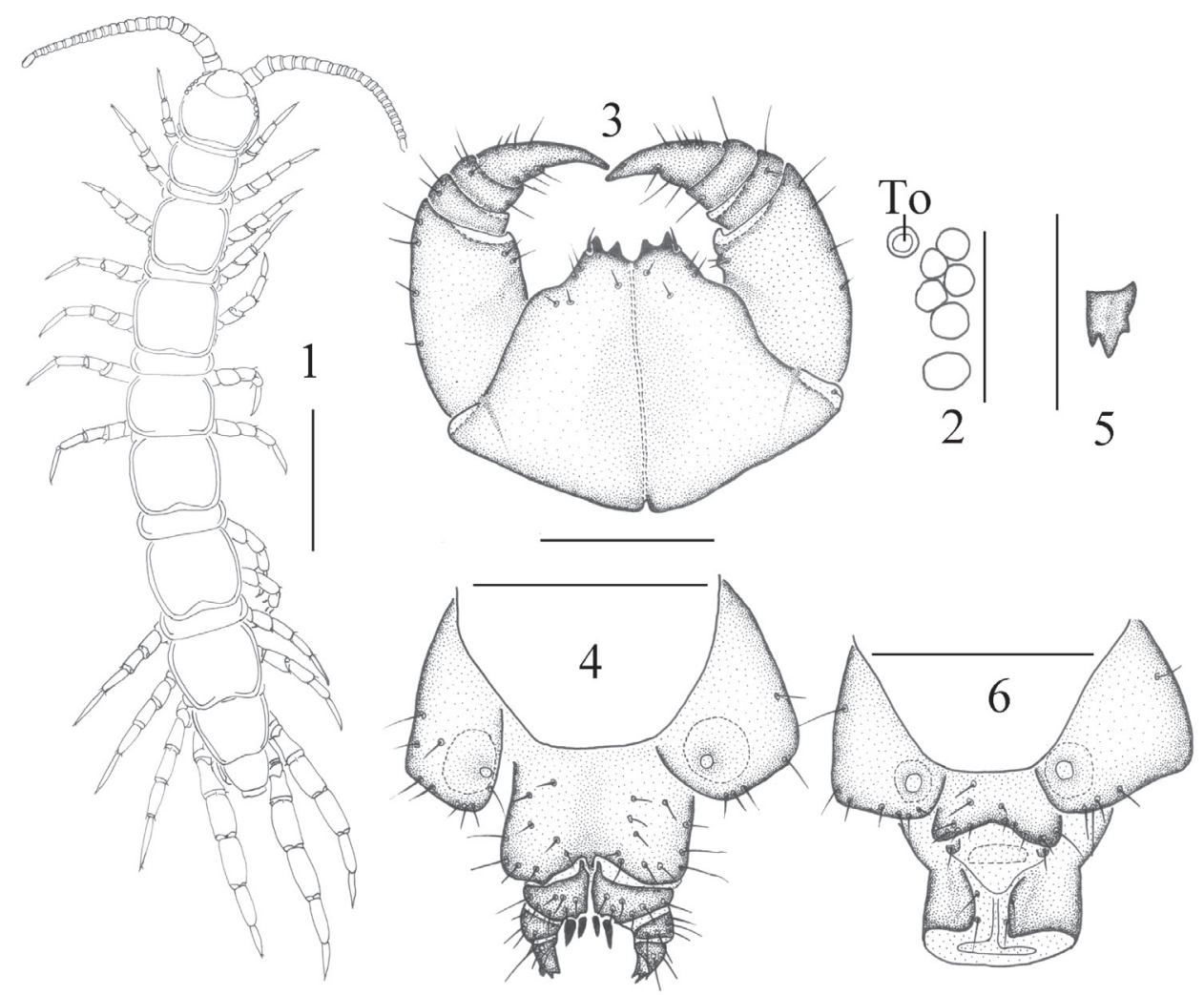

Figures I-6. Lithobius (Monotarsobius) monoforaminis sp. n., I-3 holotype, male I habitus, dorsal view, scale $1 \mathrm{~mm} \mathbf{2}$ ocelli and Tömösváry's organ (To), lateral view, scale $250 \mu \mathrm{m} \mathbf{3}$ forcipular segment, ventral view, scale $500 \mu \mathrm{m}$ 4-5 paratype, female $\mathbf{4}$ posterior segments and gonopods, ventral view, scale $500 \mu \mathrm{m}$ 5 right gonopod, ventral view, scale $250 \mu \mathrm{m} 6$ holotype, male: posterior segments and gonopods, ventral view, scale $500 \mu \mathrm{m}$.

cephalic plate, T3 slightly narrower than the cephalic plate; posterior margin of T 1 slightly convex or straight, posterior margin of $\mathrm{T} 3$ straight, posterior margin of TT 5, 8, 10, 12 and 14 slightly concave, posterior margin ridge of TT 3, 5, 8, 10 and 12 continuous; all posterior angles generally rounded, without triangular projections; lateral margin ridge of all tergites continuous; tiny setae scattered very sparsely over the surface.

Sternites: narrower posteriorly, generally trapeziform, comparatively smooth, setae emerging from pores scattered very sparsely over the surface, 1-3 slightly long setae on the surface of the anterior part of each sternite, 1-2 slightly long setae on the surface of the posterior part of each sternite.

Legs: strong, tarsi fused on legs 1-13, well-defined on legs 14 and 15; all legs with claws, fairly long, curved ventrad; anterior and posterior accessory spines on legs 1-14, the anterior one moderately slender, forming a small angle with the claw, the posterior 
spine short and strong, forming a large angle with the claw; no accessory spines on legs 15. Short to comparatively long setae scattered very sparsely over the surface of all segments of all legs, more setae scattered on the surface of tarsus; legs 14 and 15 thicker and stronger than other legs in the male; tarsus 14.4-5.5 times as long as wide, tarsus 2 about $73.3 \%-95.7 \%$ length of tarsus on legs 15 . Plectrotaxy as in Table 1.

Coxal pores: 1111, round; coxal pore field set in a relatively shallow groove, the fringe of coxal pore-field with slightly eminence.

Female S 15: generally trapeziform, anterior half being broader posterior margin straight, long setae scattered sparsely over the surface; the sternite of genital segment well chitinised, wider than long; posterior margin of genital sternite deeply concave between the condyles of gonopods, except for a small, median approximately fingerlike bulge; short to long setae sparsely scattered over the ventral surface of the genital segment. Female gonopod: first article fairly broad, bearing 6-8 long setae, arranged in 3 irregular rows; $2+2$ moderately small, coniform spurs, inner spur smaller (Fig. 4); second article with 3-4 rather long setae arranged in 2 irregular rows on its ventral side and two stout dorsolateral setae; third article usually with 2-3 long setae on its ventral surface and one stout dorsolateral seta; terminal claw tridentate, outer and inner denticles smaller than the middle one (Fig. 5).

Male S 15: trapeziform, the anterior half being broader; posterior margin straight, long setae scattered sparsely over the surface. Male first genital sternite: wider than long, usually well chitinized; posterior margin quite deeply concave between the gonopods, no bulge medially; comparatively long setae evenly scattered on the ventral surface, few setae near the $S$ 15; gonopods short and small, with 1-2 long setae, apically slightly chitinized (Fig. 6).

Habitat preferences. The specimens were collected under stones and in leaf litter in a Larix forest.

Remarks. $L$. (M.) monoforaminis sp. $\mathrm{n}$. is morphologically close to $L$. (M.) minimus Farzalieva, 2006 from Eastern Kazakhstan, with which it shares the following mutual characters: terminal claw of female gonopods tridentate, antennae commonly of 20 articles and two stout dorsolateral setae on the second article of female gonopod. The new species can

Table I. Plectrotaxy of Lithobius (Monotarsobius) monoforaminis sp. n.

\begin{tabular}{c|c|c|c|c|c|c|c|c|c|c}
\hline \multirow{2}{*}{ legs } & \multicolumn{9}{|c|}{ ventral } & \multicolumn{5}{c}{ dorsal } \\
\cline { 2 - 11 } & $\mathbf{C}$ & $\mathbf{t}$ & $\mathbf{P}$ & $\mathbf{F}$ & $\mathbf{T i}$ & $\mathbf{C}$ & $\mathbf{t}$ & $\mathbf{P}$ & $\mathbf{F}$ & $\mathbf{T i}$ \\
\hline 1 & & & $\mathrm{p}$ & $\mathrm{am}$ & $\mathrm{m}$ & & & $\mathrm{p}$ & $\mathrm{ap}$ & $\mathrm{a}$ \\
\hline $2-10$ & & & $\mathrm{p}$ & $\mathrm{am}$ & $\mathrm{m}$ & & & $\mathrm{p}$ & $\mathrm{ap}$ & $\mathrm{ap}$ \\
\hline 11 & & & $\mathrm{p}$ & $\mathrm{am}$ & $\mathrm{m}$ & & & $\mathrm{p}$ & $\mathrm{ap}$ & $\mathrm{ap}$ \\
\hline 12 & & & $\mathrm{p}$ & $\mathrm{am}$ & $\mathrm{m}$ & & & $\mathrm{mp}$ & $\mathrm{p}$ & $\mathrm{p}$ \\
\hline 13 & & & $\mathrm{mp}$ & $\mathrm{m}$ & $\mathrm{am}$ & & & $\mathrm{mp}$ & $\mathrm{p}$ & $\mathrm{p}$ \\
\hline 14 & & $\mathrm{~m}$ & $\mathrm{mp}$ & $\mathrm{m}$ & & $\mathrm{a}$ & & $\mathrm{mp}$ & & \\
\hline 15 & & $\mathrm{~m}$ & $\mathrm{mp}$ & $\mathrm{m}$ & & $\mathrm{a}$ & & $\mathrm{mp}$ & & \\
\hline
\end{tabular}


be readily could be readily distinguished from the latter by having male tibia 15 without a distodorsal, elongate wart with a crater at apex and coxal pores and the $15^{\text {th }}$ ventral plectrotaxy 01210 (vs. 01320). L. (M.) monoforaminis sp. n. differs from L. (M.) ketmenensis Farzalieva, 2006 and L. (M.) amplinus Farzalieva, 2006 by having fewer ocelli and coxal pores, different plectrotaxy and lacking modifications on male tibia 15 .

\section{Key to the Chinese species of Lithobius (Monotarsobius)}

To assist in the identification of the Chinese species of Lithobius (Monotarsobius), the following key is offered. This key emphasizes characters that can be examined without high-magnification microscopy; moreover, these characters are specific to the taxa occurring in China.

1 Four ocelli on each side of cephalic plate, $17+17$ antennal articles

L. (M.) crassus (Loksa, 1965)

- $\quad$ Five or more ocelli on each side of cephalic plate, not less than $18+18$ antennal articles Second article of female gonopod with three dorsolateral setae, 2222-3443 coxal pores Second article of female gonopod with two dorsolateral setae, 1111-2222 coxal pores

Terminal claw of the female gonopod simple

L. (M.) ramulosus (Takakuwa, 1941)

Terminal claw of the female gonopod bidentate or tridentate

Tömösváry's organ slightly smaller than adjoining ocellus; terminal ocellus largest L. (M.) songi Pei, Ma, Shi, Wu, Zhou, 2011 Tömösváry's organ slightly larger than adjoining ocellus or about same in size; terminal two ocelli largest

L. (M.) subspinipes Ma, Pei, Zhu, Zhang, Liu, 2009

Tömösváry's organ larger than largest ocellus, antennae 20-25 articles

Tömösváry's organ about same size as the adjoining ocelli, antennae 19 articles 


\section{Acknowledgements}

This study was supported by the National Natural Science Foundation of China (NSFC grant No. 31172057 and 30900131). We are grateful to Dr. Gregory D. Edgecombe, London, U. K., and Dr. Pavel Stoev, Sofia, Bulgaria, for their hospitality and everlasting help during our research, respectively. We thank Dr. Marzio Zapparoli, Viterbo, Italy, Dr. Rowland M. Shelley, North Carolina, USA, Dr. His-Te Shih, Taichung, China, and Ph.D Ivan H. Tuf, Olomouc, Czech Republic, for providing us with invaluable literature and comments. Thanks must go to Dr. Zi-Zhong Yang and Dr. Zhi-Sheng Zhang for their help in preparing the paper.

\section{References}

Attems C (1901) Myriopoden. In: Horváth G (Ed) Zoologische Ergebnisse der dritten asiatischen Forschungsreise des Grafen Eugen Zichy. Vol. 2. Karl W. Hiersemann, Leipzig, 275-310.

Attems C (1904) Central- und hoch-asiatische Myriopoden. Gesammelt im Jahre 1900 von Dr. von Almassy und Dr. von Stummer. Zoologische Jahrbücher Abteilung Systematik 20: $113-130$.

Attems C (1938) Die von Dr. C. Dawydoff in Französisch Indochina gesamelten Myriopoden. Memoires du Muséum National d'Histoire naturelle 6: 187-354.

Attems C (1953) Myriopoden von Indochina. Expedition von Dr C. Dawydoff. Mémoires du Muséum National d'Histoire Naturelle 5: 131-199.

Bonato L, Edgecombe GD, Lewis JGE, Minelli A, Pereira LA, Shelley RM, Zapparoli M (2010) A common terminology for the external anatomy of centipedes (Chilopoda). ZooKeys 69: 17-51. doi: 10.3897/zookeys.69.737

Chamberlin RV, Wang YHM (1952) Some records and descriptions of chilopods from Japan and other Oriental areas. Proceedings of the Biological Society of Washington 65: 177-188.

Chao JL (2005) Review and development of study on Chilopoda of Taiwan. Journal of Endangered Wild Animal 9: 33-41.

Dányi L, Tuf IH (2012) Lithobius (Monotarsobius) franciscorum sp. nov., a new lithobiid species from the Altai, with a key to the Central Asian species of the subgenus (Chilopoda: Lithobiomorpha). Zootaxa 3182: 16-28.

Dobroruka LJ (1960) Über eine kleine Chilopoden-Ausbeute aus der Mongolei. Acta Arachnologica 17: 15-18. doi: 10.2476/asjaa.17.15

Dobroruka LJ (1979) Zur weiteren Kenntnis der zentralasiatischen Chilopoden. Věstník Československé společnosti zoologické 43: 161-164.

Eason EH (1992) On the taxonomy and geographical distribution of the Lithobiomorpha. In Meyer E, Thaler K, Schedl W (Eds) Advances in Myriapodology. Berichte des naturwissenschaftlich-medizinischen Vereins in Innsbruck, Supplement 10: 1-9.

Eason EH (1997) On some Lithobiomorpha from the mountains of Kirghizia and Kazakhstan (Chilopoda). Arthropoda Selecta 6: 117-121. 
Farzalieva GS (2006) New species of the lithobiid genus Lithobius (Monotarsobius) (Chilopoda: Lithobiomorpha: Lithobiidae) from Eastern Kazakhstan. Arthropoda Selecta 15: 99-117. Farzalieva GS, Zalesskaja NT (2002) On two remarkable species of lithobiid centipedes (Chilopoda: Lithobiomorpha: Lithobiidae) from steppe of the southern Urals, Russia. Arthropoda Selecta 11: 265-269.

Ma H, Song D, Zhu M (2007a) A new genus and two new species of lithobiid centipedes (Chilopoda: Lithobiomorpha) from China. Zootaxa 1460: 25-34.

Ma H, Song D, Zhu M (2007b) Review of Cermatobius Haase, 1885 (Chilopoda: Henicopidae) of China and neotype designation for Cermatobius longicornis (Takakuwa, 1939). Zootaxa 1608: 21-30.

Ma H, Song D, Zhu M (2008a) A new species of the Genus Australobius Chamberlin,1920 (Lithobiomorpha: Lithobiidae) from Tibet, China. Entomological News 119 (2):171-177. doi: 10.3157/0013-872X(2008)119[171:ANSOTG]2.0.CO;2

Ma H, Song D, Zhu M (2008b) A review of the Chinese species of Bothropolys Wood, 1862 (Chilopoda: Lithobiomorpha: Lithobiidae). Zootaxa 1786: 35-47.

Ma H, Pei S, Zhu M, Zhang G, Liu L (2009) A new species of Lithobius (Monotarsobius) Verhoeff, 1905 (Lithobiomorpha: Lithobiidae) from China. Entomological News 120 (3): 313-318. doi: 10.3157/021.120.0310

Pei S, Ma H, Shi B, Wu D, Zhou W. (2011) A new species of Lithobius (Monotarsobius) Verhoeff, 1905 (Lithobiomorpha, Lithobiidae) from China. ZooKeys 82: 59-66.

Pocock RI (1895) Report upon the Chilopoda and Diplopoda obtained by P. W. BassettSmith Esq. Surgeon R. N. and J. J. Walker Esq. R. N. during the cruise in the Chinese seas of H. M. S. "Penguin" Commander W. U. Moore commanding. Annals and Magazine of Natural History 6 (15): 346-372. doi: 10.1080/00222939508677895

Takakuwa Y (1939) 9 Bothropolys-Arten aus Japan. Transactions of the Natural History Society of Formosa 29 (188): 103-110.

Takakuwa Y (1940) Class Chilopoda, Epimorpha, Lithobiomorpha. Fauna Nipponica Vol. 9 Fas. 8 No. (3). Sanseido Book Store, Tokyo, 104 pp.

Takakuwa Y (1941) Über einige japanische Lithobiiden. Transactions of the Natural History Society of Formosa 31: 292-298.

Takakuwa Y (1942) Die Myriopoden aus Formosa Philippinien u.s.w. Transactions of the Natural History Society of Formosa 32: 359-367.

Takakuwa Y, Takashima H (1949) Myriapods collected in Shansi, North China. Acta Arachnologica (11) 1-2: 51-69. doi: 10.2476/asjaa.11.51

Trotzina A (1895) Vier neue Lithobius-Arten aus Central Asia. Horae Societatis Entomologicae Rossicae 28: 247-253.

Wang D, Mauriès JP (1996) Review and perspective of study on myriapodology of China. In: Geoffroy JJ, Mauriès JP, Nguyen Duy-Jacquemin M (Eds) Acta Myriapodologica. Mémoires du Museum National d'Histoire Naturelle 169: 81-99.

Wang YHM (1959) On Chilopoda from Taiwan with a new lithobid. Quarterly Journal of the Taiwan Museum 12 (3-4): 195-199. 
Wang YHM (1963) Millipedes and Centipedes of Quemoy, Fukien Province and Taiwan island, Botel Tobago (Lan Yu), Taiwan Province and of Singapore. Quarterly Journal of the Taiwan Museum 16 (1-2): 89-96.

Zalesskaja NT (1978) Identification book of the lithobiomorph centipedes of the USSR (Chilopoda: Lithobiomorpha) [in Russian]. Moscow, Nauka Publ. House, 212 pp.

Zapparoli M (2006) Lithobiidae. In: Minelli A (Ed) ChiloBase. A world catalogue of Centipedes (Chilopoda), http://chilobase.bio.unipd.it

Zapparoli M, Edgecombe GD (2011) Order Lithobiomorpha. In: Minelli A (Ed) Myriapoda, Vol. 1. Brill, Leiden, Boston: 371-389.

Zhang C (1996) Chilopoda: Lithobiomorpha. In: Wu S, Feng Z (Eds) The biology and human physiology in the Hoh Xil region. Sci. Press: Beijing, 244-251. 